\title{
RENKOHO \\ MANTENIENDO UN CUERPO FLEXIBLE \\ PARA LOGRAR LA SALUD Y LA LONGEVIDAD
}

\section{Exención}

Este artículo describe ejercicios que pueden reportar beneficios para la salud. A pesar de ello, y por precaución, los lectores deben consultar a un médico antes de realizar los mismos. Léase el texto de exención en la página 2 de la revista.
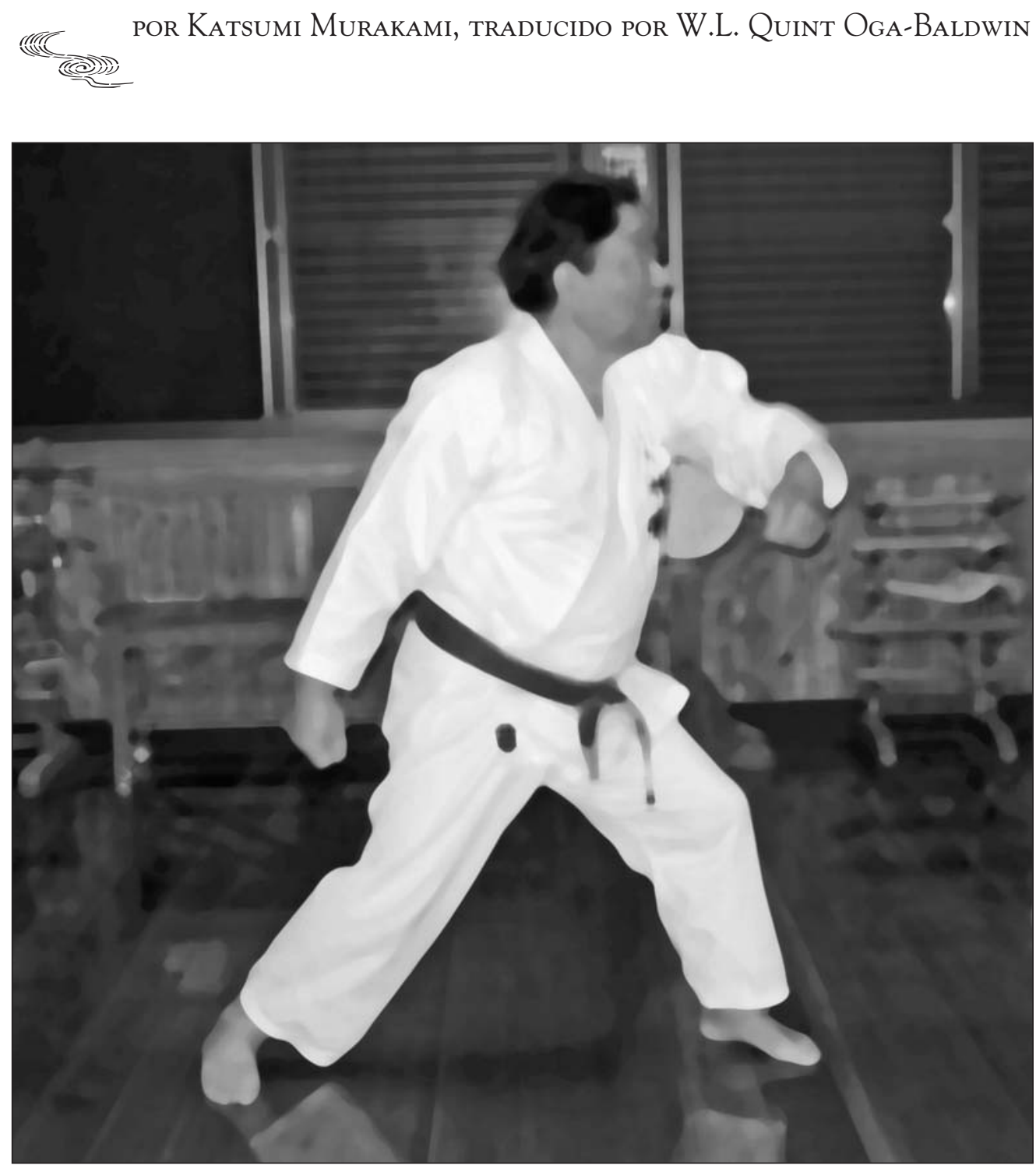

\section{Resumen}

Durante casi 60 años Murakami Katsumi (nacido en 1927) ha sido practicante de Karate-do de Okinawa y de otras artes marciales. Estudió artes marciales chinas con Sato Kinbei (nacido en 1926). A pesar de su avanzada edad, aún se mueve como un hombre mucho más joven, una recompensa a su diligencia en el seguimiento de las artes marciales como disciplinas físicas, mentales y espirituales. Este artículo se ha extraído de su libro Karate no Kokoro to Waza (El espíritu y las técnicas del kárate), y detalla los ejercicios que ha creado para preparar el cuerpo para el entrenamiento en las artes marciales y para alargar la propia vida a través de la práctica de la buena salud. Todos los ejercicios que se muestran en este artículo están realizados por el propio autor. 


\section{Manteniendo un cuerpo flexible}

Aquellos que practican kárate deben evitar cualquier agarrotamiento del cuerpo. La flexibilidad y la elasticidad son extremadamente importantes. Se dice que ser joven es ser flexible y elástico. A medida que las personas envejecen, sus cuerpos se deterioran, su flexibilidad se pierde y se vuelven más tensos y frágiles. A medida que el cuerpo se endurece, envejece y se deteriora, la duración de la vida se acorta.

Las personas son, en términos generales, totalmente adultas cuando alcanzan la edad de 25 años. A partir de ahí, se envejece de forma natural. El tema crucial, entonces, es a qué ritmo envejece y se deteriora el cuerpo. El kárate, sin que haya excepción al respecto, es extremadamente efectivo para enlentecer este proceso de deterioro y puede ayudar a preservar la juventud.

En relación a esta última afirmación, Motobu Choki cuenta una valiosa historia que aprendió de Itosu (Anko):

Itosu cuenta de Bushi Nagahama, que vivía en Tsujimenumo, y de cómo entrenaba. Nagahama era únicamente un año mayor que Itosu, pero Itosu lo respetaba no sólo como a un mayor sino también como profesor, y como tales, los dos eran buenos amigos.

Itosu me contó la siguiente historia como algo secreto.

Cuando Bushi Nagahama estaba enfermo en la cama y supo que sus perspectivas eran bastante malas, un día me llamó a su lecho para transmitirme sus últimas peticiones...

"Itosu, mi tiempo se está acabando y estoy preparado para lo que vaya a venir; pero mientras medito sobre mi vida, me doy cuenta de que he cometido un gran error. Te he Ilamado aquí para que oigas mis últimas palabras; por tanto, escucha con atención. En mi forma de entrenamiento hice a mi cuerpo muy tenso e inflexible con el objeto de desarrollar fuerza. He pensado mucho sobre esto y me he dado cuenta de que fue un error. Me pregunto si haciendo mi cuerpo duro y fuerte, en realidad lo hice más débil. A ti también se te dijo que endurecieses tu cuerpo, pero a partir de mi experiencia vital me doy cuenta de que esto fue una pobre elección, y por tanto te digo, que si enseñas a tus alumnos de este modo, será un terrible crimen, y debes corregirlos". Éste fue el deseo final de Nagahama, dijo Itosu. También la gente joven debería escuchar y aprender de esta historia.

Esta historia debería ilustrar hasta qué punto endurecer demasiado el cuerpo para desarrollar fuerza y potencia hará al cuerpo más débil, tal y como le sucedió a Nagahama. Por ejemplo, observando las caderas y la parte baja de la espalda, si las caderas carecen de flexibilidad todo lo demás estará mal. No serás capaz de mover tu cuerpo. Si quieres mover tu cuerpo ágilmente, tienes que hacer que tu cuerpo esté relajado y flexible. Esto es lo que se hace en muchos estilos de artes marciales, pero especialmente en kárate, uno necesita ser capaz de moverse en un parpadeo de ojos, y sin esta velocidad el kárate es inútil. Estos movimientos ágiles no pueden realizarse si el cuerpo está tenso. Por tanto, para aprender las aplicaciones del kata y sus verdaderos significados, se necesita otro dispositivo. En este sentido, al principio de mi plan de entrenamiento realizo una serie de ejercicios que podrían llamarse Renkoho, o un modo de entrenamiento. Estos ejercicios entrenan la energía interna $(k i)$, trabajan la flexibilidad, y mejoran la respiración. A continuación explicaré estos ejercicios.

\section{Ejercicio I}

En una postura natural, elimina toda la tensión muscular de tu cuerpo y balancea las caderas. Mientras giras tus caderas de izquierda a derecha y al revés, deja que tus brazos también se balanceen con tu cuerpo. Mueve los brazos lentamente, rítmicamente, de un modo relajado, sin tensión y sin usar la musculatura. Este es un ejercicio que se realiza en China para preparar el cuerpo, y es muy bueno para la salud. Debe realizarse muchas veces, pero realiza de 20 a 30 repeticiones cada vez y después pasa al siguiente ejercicio.
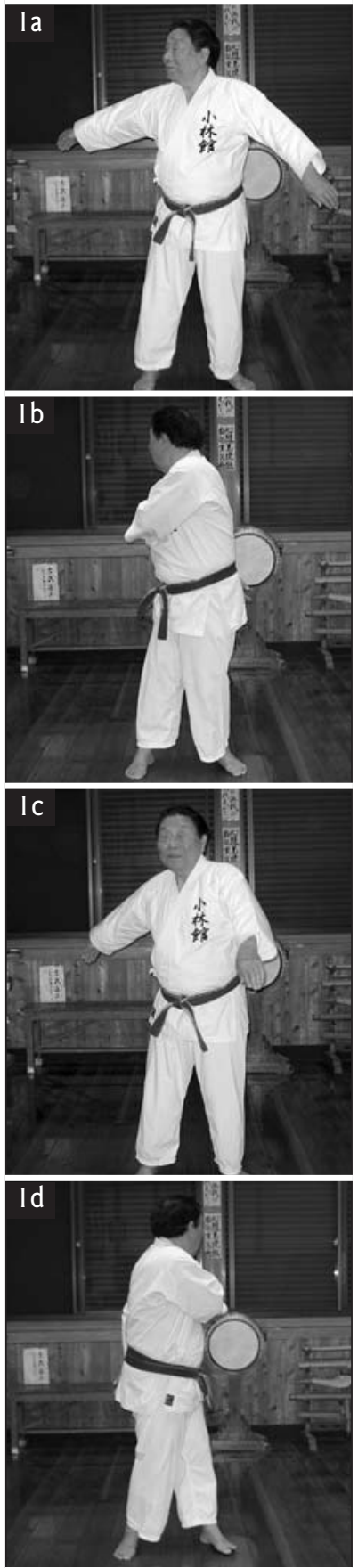

Revista de Artes Marciales Asiáticas $\diamond$ Volumen 4 Número 1 (94-103) - 2009 


\section{Ejercicio 2}

En la misma postura natural, eleva ambos brazos hasta la altura de los hombros. Desde allí, en un movimiento, lleva tus brazos hacia abajo como si estuvieses arrojando agua hacia atrás. Otra vez, tu cuerpo debe estar muy relajado y deberías balancear lentamente tus brazos en un ritmo como "1,2 .. 1,2". Debes mantener tus brazos tan rectos como sea posible, e imaginar que estás echando agua o utilizando las palmas de tus manos para remar. Al final del movimiento, permite una ligera flexión de tus muñecas. Este ejercicio es bueno para crear un espíritu relajado, así como para disminuir la presión sanguínea. También debe realizarse de 20 a 30 veces antes de pasar al siguiente ejercicio.

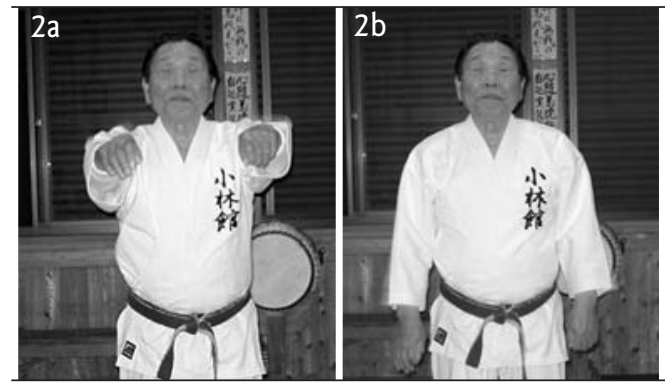

\section{Ejercicio 3}

Otra vez en una postura natural, lleva tus brazos hacia adelante, y después cambia la dirección hacia atrás. Esto también debe realizarse lentamente, sin tensión muscular y con los brazos extendidos tan lejos como sea posible, balanceando los brazos hacia adelante y hacia atrás como dibujando un gran círculo en el aire. Haz esto 20 o 30 veces y después pasa al siguiente ejercicio.
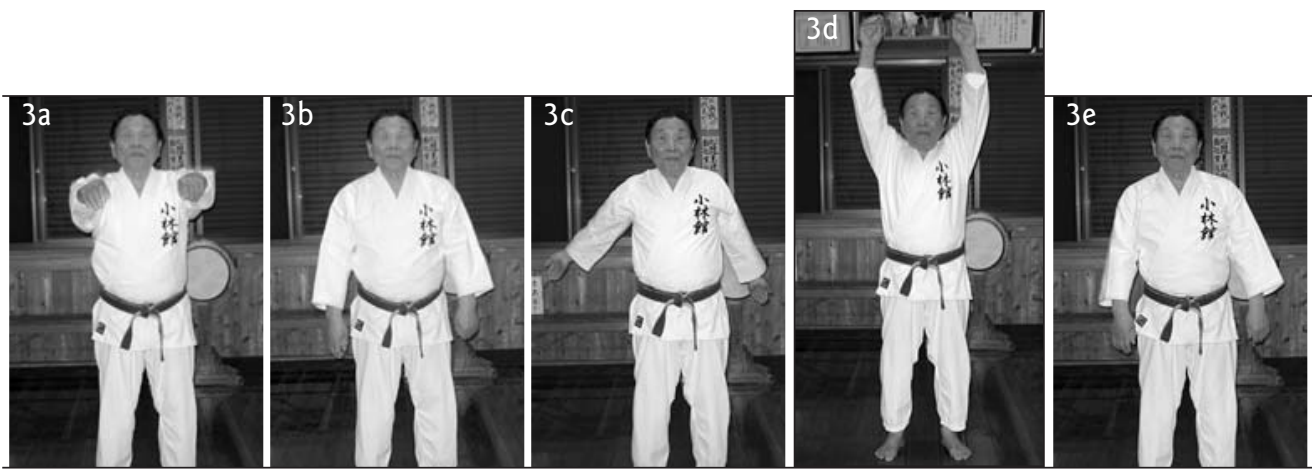

\section{Ejercicio 4}

Manteniendo una postura natural, mueve tus brazos a una posición cruzada frente a tu cara, después llévalos otra vez hacia abajo y balancéalos a los lados, sobre tu cabeza y frente a tu cuerpo en un gran círculo, y después otra vez hacia los lados. Continuando el movimiento, cambia la dirección hacia abajo y luego eleva los brazos, cruzándolos frente a tu cara y después por encima de tu cabeza en un amplio movimiento circular, hacia el lado, abajo, y luego de nuevo hacia arriba frente a tu cara. Esto se realiza con los brazos rectos y con el cuerpo relajado. Haciendo este ejercicio y el anterior se aliviará al cuerpo de la rigidez en los hombros. Completa 20 o 30 rotaciones, y después continúa.
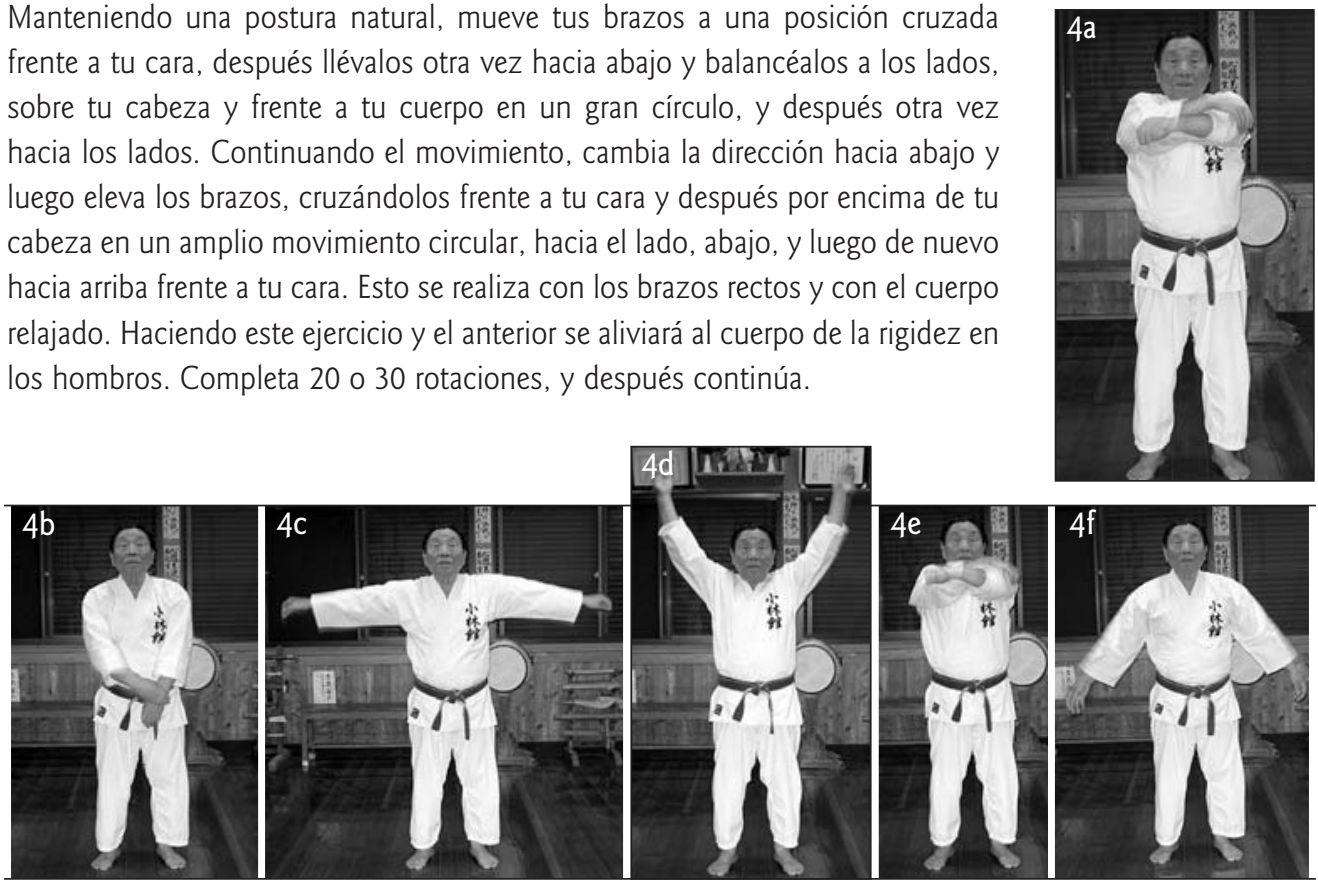

Renkoho manteniendo un cuerpo flexible... $\quad \diamond \quad$ Katsumi Murakami 


\section{Ejercicio 5}

Abre un poco las piernas y flexiona el cuerpo a la altura de la cintura, doblándote directamente hacia los lados, lentamente, suavemente, de un modo relajado. Cuando te flexiones hacia la izquierda, deja que tu mano izquierda cuelgue hacia tu talón izquierdo y lleva la mano derecha hacia arriba y déjala colgar de tal modo que la parte interna del brazo toque la oreja o la parte superior de la cabeza. Cuando te flexiones hacia la derecha, haz lo mismo que hacia la izquierda pero con las manos y brazos contrarios. Repite el ejercicio entre 20 y 30 veces, y luego comienza con el siguiente.
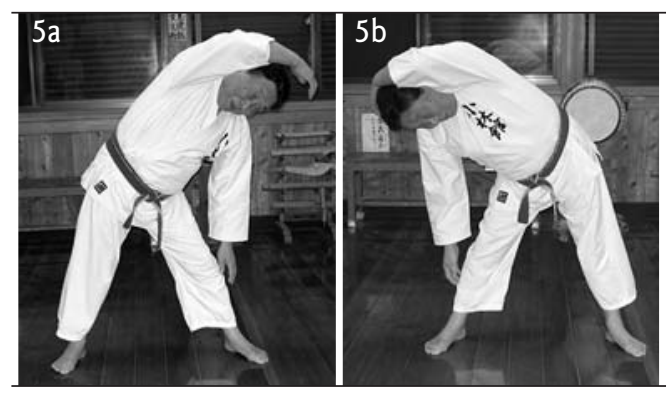

\section{Ejercicio 6}

Abriendo las piernas del mismo modo que en el ejercicio anterior, lleva ambos brazos horizontalmente hacia los lados a la altura de los hombros, y manteniendo esa posición, gira la parte superior de tu cuerpo diagonalmente hacia la izquierda mientras te flexionas hacia adelante. Con los brazos abiertos, trata de tocar con la palma de tu mano derecha el suelo delante de tu pie izquierdo, mientras tu mano izquierda apunta hacia arriba hacia el techo. Tu cabeza debería estar girada de tal modo que estarías mirando a las yemas de los dedos de tu mano izquierda. Eleva tu cuerpo lentamente, manteniendo los brazos abiertos horizontalmente, y después bájalos hacia los lados. Eleva tus brazos de nuevo, y luego flexiónate hacia delante diagonalmentehacia la pierna contraria y completa el mismo ejercicio por el lado contrario. Mientras haces esto, mantén la misma sensación de relajación en tu cuerpo mientras te flexionas hacia delante. Una vez que hayas hecho esto de 20 a 30 veces, con-
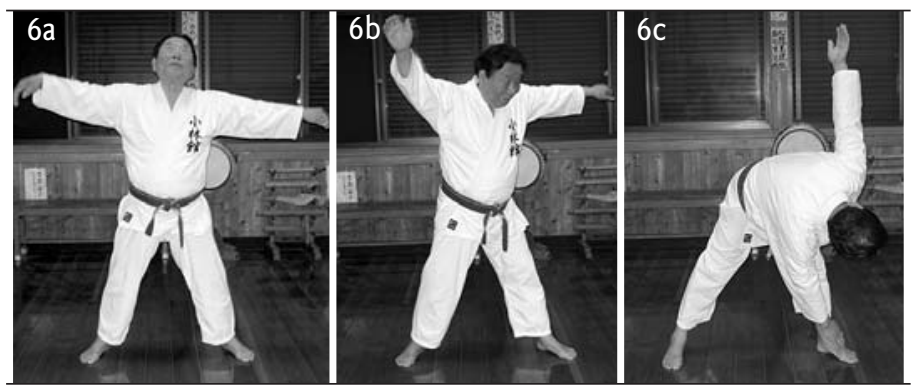
tinúa con el ejercicio siete.

\section{Ejercicio 7}

En la misma posición ligeramente abierta, desliza tus brazos sobre tu pecho y elévalos por encima de tu cabeza con las palmas mirando hacia arriba, después flexiona tu cuerpo tanto como puedas hacia atrás, Ilevando tus brazos detrás de ti y girando la cara para mirar hacia atrás. A continuación, vuelve gradualmente a una posición recta, llevando los brazos por encima y hacia adelante. Después, gradualmente, flexiona la parte superior del cuerpo hacia delante a la altura de la cintura, llevando las palmas de las manos hacia abajo hacia ambos tendones de Aquiles, pellizcando levemente el tendón. Después, lentamente, devuelve tu cuerpo a su posición original. Repite lentamente este ejercicio, relajando tu cuerpo según lo realizas. Cuando te flexiones hacia atrás, inhala profundamente, y después exhala mientras vuelves y te flexionas hacia delante. Mientras recuperas la posición, inhala y exhala en silencio. Repite este ejercicio unas 10 veces, y luego continúa.
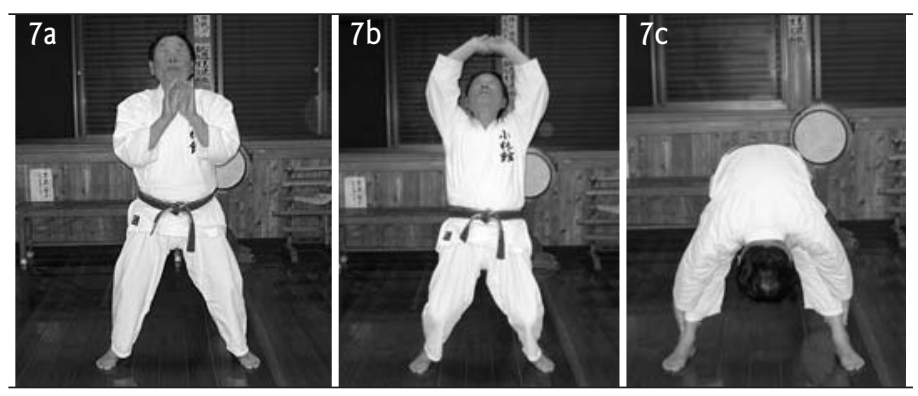

Revista de Artes Marciales Asiáticas $\diamond$ Volumen 4 Número 1 (94-103) - 2009 


\section{Ejercicio 8}

Volviendo a una posición natural, inspira y lleva tus brazos hacia arriba justo debajo de los pectorales, con las manos en forma de puño como cuando se arma el brazo. Mientras exhalas, gira tu cuerpo hacia la izquierda mientras abres tu mano derecha y extiendes la palma. Mientras haces esto, gira tu mano de modo que los dedos de tu mano derecha estén hacia arriba. A medida que giras lentamente tu cuerpo, imagina que hay un muro frente a ti y que estás empujando ese muro con la palma. Al mismo tiempo, haciendo juego con el giro del cuerpo hacia la izquierda y el empuje con la mano derecha, con la mano izquierda en forma de puño lleva el codo izquierdo hacia atrás. Mientras haces esto, gira tu cara hacia atrás para mirar a tu codo izquierdo que está detrás de ti. Todo esto se realiza mientras se espira. A continuación inspira mientras vuelves a la posición inicial, con ambos brazos armados en la parte lateral del cuerpo, y finalmente exhalando mientras los dejas caer a ambos lados en una posición natural. Además de esto, mientras giras la parte superior del cuerpo, asegúrate de no estropear la posición de la parte inferior. A continuación completa el movimiento por el otro lado, empujando hacia adelante con la mano izquierda y llevando atrás la derecha. Haz esto 10 veces, y después comienza el siguiente ejercicio.
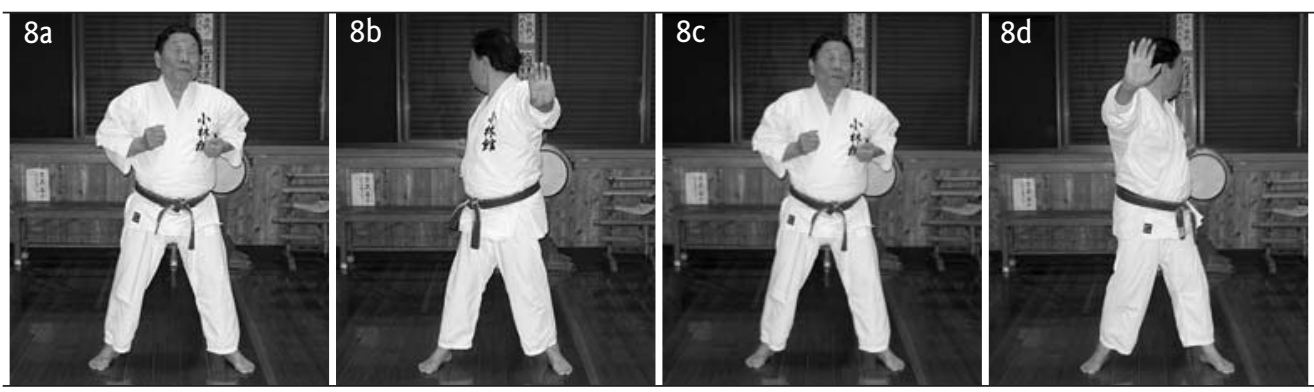

\section{Ejercicio 9}

En una posición natural, arma tus brazos, mientras inspiras en la misma posición que en el ejercicio anterior, justo por debajo de los músculos del pecho. Espirando lentamente, gira el cuerpo hacia la izquierda y abre tu puño derecho adoptando la mano en forma de lanza (nukite) con el pulgar hacia arriba, y gradualmente lleva la mano hacia la izquierda. Inspirando, devuelve la parte superior del cuerpo a la posición inicial, mirando hacia adelante con ambos brazos armados bajo los pectorales. Exhala lentamente, y deja que tus manos cuelguen en una posición natural. Repite el ejercicio con la mano izquierda girando hacia la derecha. Completa 10 repeticiones y continúa.
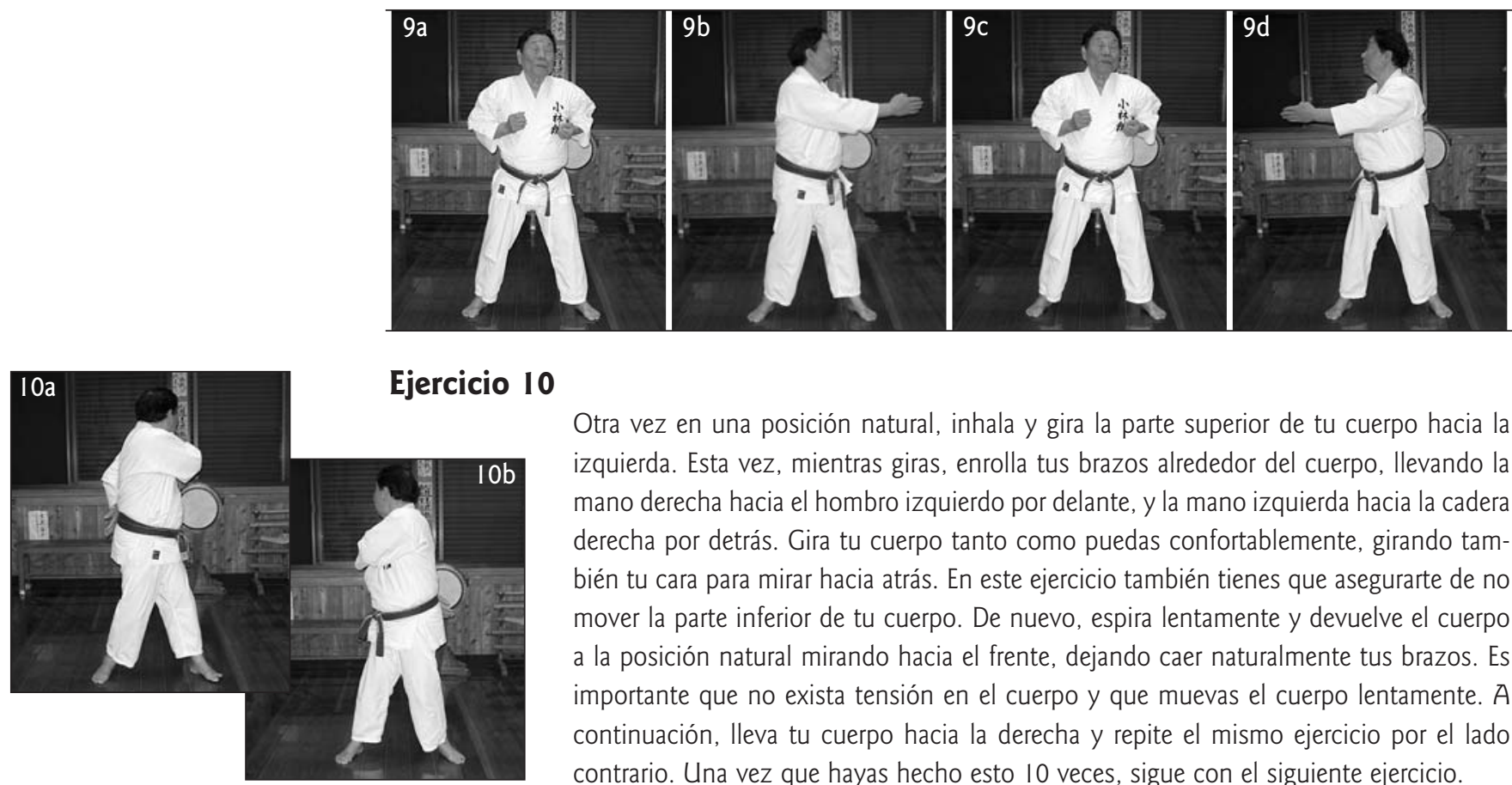

Otra vez en una posición natural, inhala y gira la parte superior de tu cuerpo hacia la izquierda. Esta vez, mientras giras, enrolla tus brazos alrededor del cuerpo, llevando la mano derecha hacia el hombro izquierdo por delante, y la mano izquierda hacia la cadera derecha por detrás. Gira tu cuerpo tanto como puedas confortablemente, girando también tu cara para mirar hacia atrás. En este ejercicio también tienes que asegurarte de no mover la parte inferior de tu cuerpo. De nuevo, espira lentamente y devuelve el cuerpo a la posición natural mirando hacia el frente, dejando caer naturalmente tus brazos. Es importante que no exista tensión en el cuerpo y que muevas el cuerpo lentamente. A continuación, lleva tu cuerpo hacia la derecha y repite el mismo ejercicio por el lado contrario. Una vez que hayas hecho esto 10 veces, sigue con el siguiente ejercicio.

Renkoho manteniendo un cuerpo flexible... $\quad \checkmark$ Katsumi Murakami 


\section{Ejercicio I I}

Junta tus pies y eleva ambas manos por encima de tu cabeza, juntando los pulgares e índices para hacer un triángulo sobre tu cabeza. En esta postura, mantén el equilibrio, flexiona las rodillas y ponte en cuclillas. Ambos muslos deberían abrirse a los lados tanto como sea posible, tu cuerpo no debería flexionarse hacia
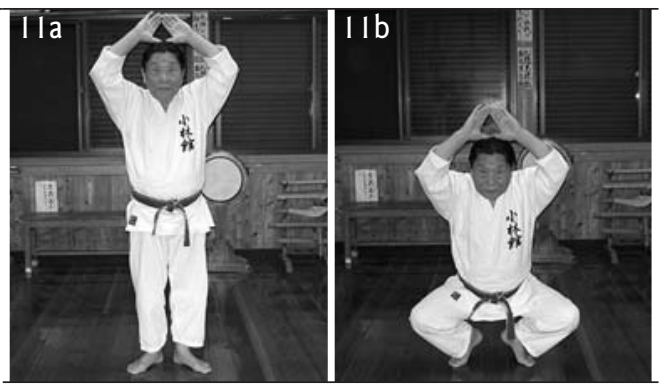
adelante, y la columna vertebral debería mantenerse recta. A continuación, ponte en pie y vuelve a la postura original. Deja tus manos en la posición en triángulo sobre tu cabeza y no bajes los brazos. Repite el ejercicio. El dejar caer el cuerpo y después elevarse debería realizarse lentamente. Este ejercicio generará fuerza en tus piernas y caderas. La respiración en este ejercicio debe ser natural. Otra vez, completa 10 o 20 repeticiones, y continúa.

\section{Ejercicio 12}

Extendiendo tu pierna izquierda hacia el lado izquierdo, desciende tus caderas y lleva la palma de la mano izquierda a la parte inferior de tu axila derecha. Mientras haces esto, lleva tu brazo izquierdo por encima de tu cabeza de tal modo que el brazo inferior esté horizontal y la palma de la mano está abierta mirando hacia adelante. En esta posición, denominada la postura del tigre agazapado, la pierna izquierda debe estar tan recta como sea posible, mientras que la derecha está completamente flexionada y las caderas estarán tan bajas como puedas. La cara debería estar mirando a la izquierda. La parte superior de tu cuerpo no debería flexionarse hacia delante. A continuación, cambia de lado y extiende la pierna derecha. Relaja tu cuerpo mientras haces esto, y repite el ejercicio 10 veces antes de continuar.
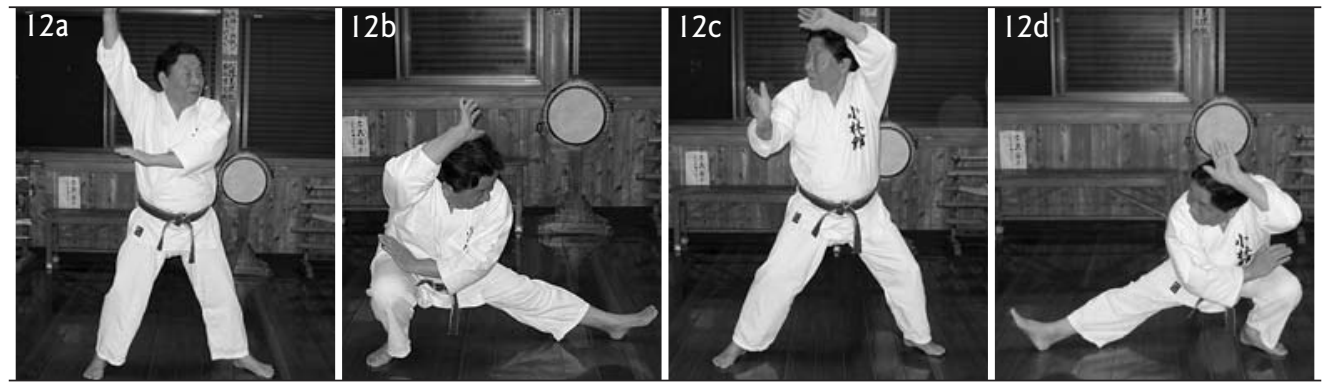

\section{Ejercicio 13}

Adopta una postura con las piernas abiertas a una anchura un poco mayor que la anchura de los hombros. Da una palmada, llevando tus manos juntas hacia la parte derecha de tu cuerpo. Mientras das la palmada, inhala. A continuación, mientras espiras, lleva tu mano derecha diagonalmente hacia abajo hacia el lado derecho del cuerpo, mientras al mismo tiempo llevas tu mano izquierda diagonalmente hacia arriba al lado izquierdo. Las palmas de ambas manos deberían estar mirando hacia abajo con las muñecas flexionadas tanto como sea posible. A continuación, inspirando, vuelve con las manos juntas al lado derecho, con tu cara mirando hacia las palmas. A continua-
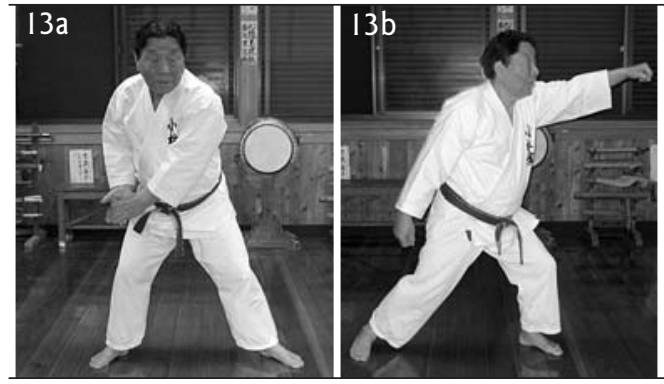
ción, espira, mientras giras tu cuerpo hacia la izquierda más que la vez anterior, inclinándote para crear una línea diagonal desde la cabeza hasta la punta del pie, y al mismo tiempo completar los mismos movimientos de brazo que anteriormente. La segunda vez implica un movimiento mucho más amplio que la primera. Los brazos y el cuerpo deberían describir una línea diagonal, y tu cara debería estar mirando hacia los dedos de tu mano izquierda. A continuación, haz el ejercicio por el lado contrario. Mientras haces este movimiento, es importante mantener ambas muñecas tan flojas y relajadas como sea posible. Haz este ejercicio lentamente y sin ninguna tensión en el cuerpo. El inspirar con un ritmo sincronizado durante el ejercicio es extremadamente importante. Después de 10 repeticiones, continúa con el siguiente ejercicio.
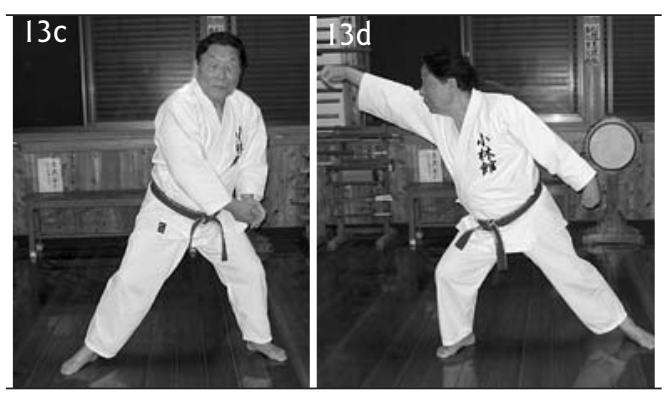

Revista de Artes Marciales Asiáticas $\diamond$ Volumen 4 Número 1 (94-103) - 2009 


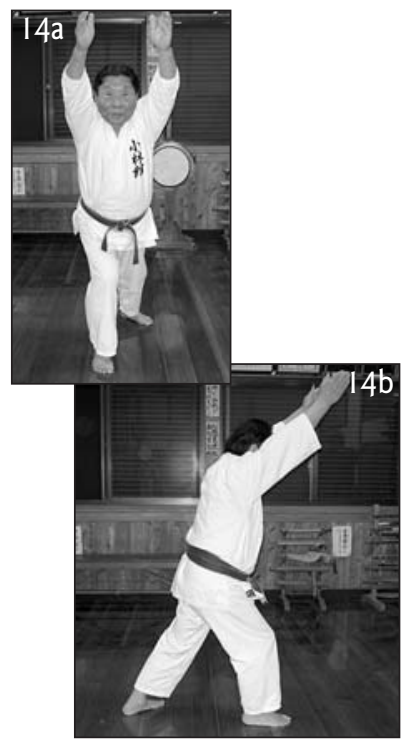

\section{Ejercicio 14}

Con los pies juntos, inhala profundamente $y$ extiende ambos brazos mientras das un paso al frente con tu pierna derecha. Flexiona profundamente tu pierna derecha, con la parte superior de tu cuerpo, brazos, y cabeza creando una línea diagonal con la pierna izquierda extendida. Mantén tus ojos mirando hacia el frente. El talón izquierdo no debería levantarse del suelo, y debe
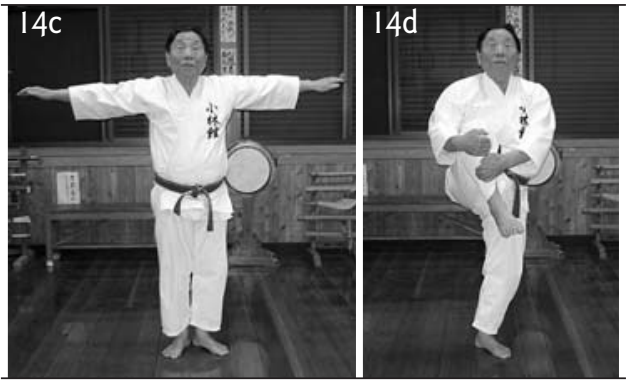
permanecer fijo al suelo como si estuviese clavado a él. Mientras espiras, extiende los brazos horizontalmente hacia los lados, con ambas palmas mirando hacia abajo. Una vez que has regresado a la posición original con los pies juntos, y aún espirando, eleva tu rodilla derecha y tira de ella hasta la altura de la axila utilizando ambas manos. Ahora libera el resto de tu espiración y devuelve la pierna a su posición original. A continuación repite el ejercicio por la parte izquierda, flexionando profundamente tu pierna izquierda. Mientras haces estos movimientos, relaja el cuerpo y muévete en armonía con la respiración. Haz esto entre 6 y 10 veces antes de pasar al siguiente ejercicio.

\section{Ejercicio 15}

Comenzando en una postura natural, inspira profundamente y pon tu mano izquierda por detrás de la espalda. Mientras espiras, gira tu cabeza hacia arriba y extiende tu brazo derecho recto por encima de la cabeza con la palma mirando al techo. Con el aire que aún te quede, lleva tu brazo derecho hacia abajo a la misma posición mientras dejas caer tu cabeza, de modo que estés mirando hacia delante, en la misma posición inicial. En este ejercicio, la sensación debería ser como si la palma estuviese empujando la viga de un tejado. Asegúrate de que tu columna vertebral está recta, y de que respiras a lo largo del ejercicio, moviéndote sin tensión. Trabajando ambos lados, haz 10 repeticiones y después continúa.
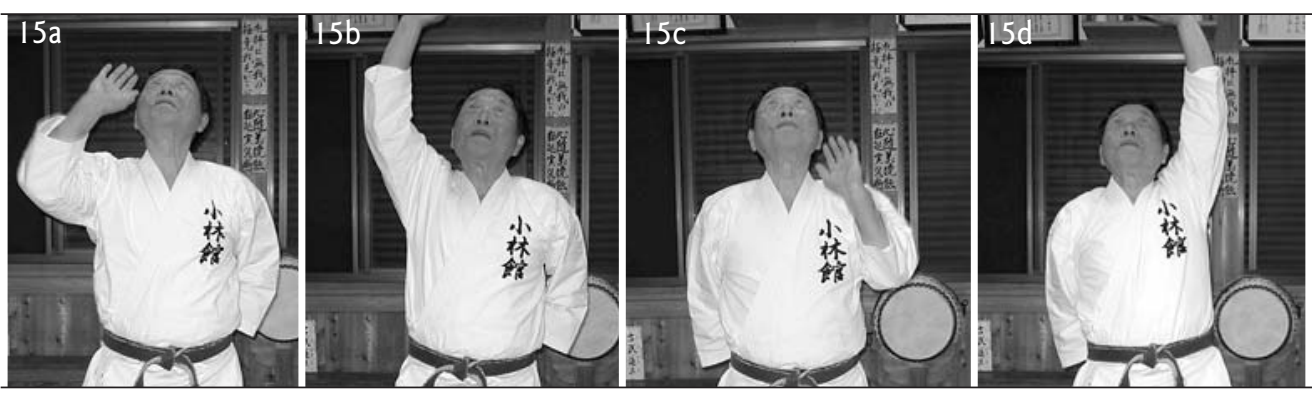

\section{Ejercicio 16}

Con tus pies juntos, mientras inspiras, cruza ambas manos frente a tu cuerpo y junta las palmas. Manteniendo esta posición, lleva tus manos rectas por encima de la cabeza, extendiendo los brazos tan
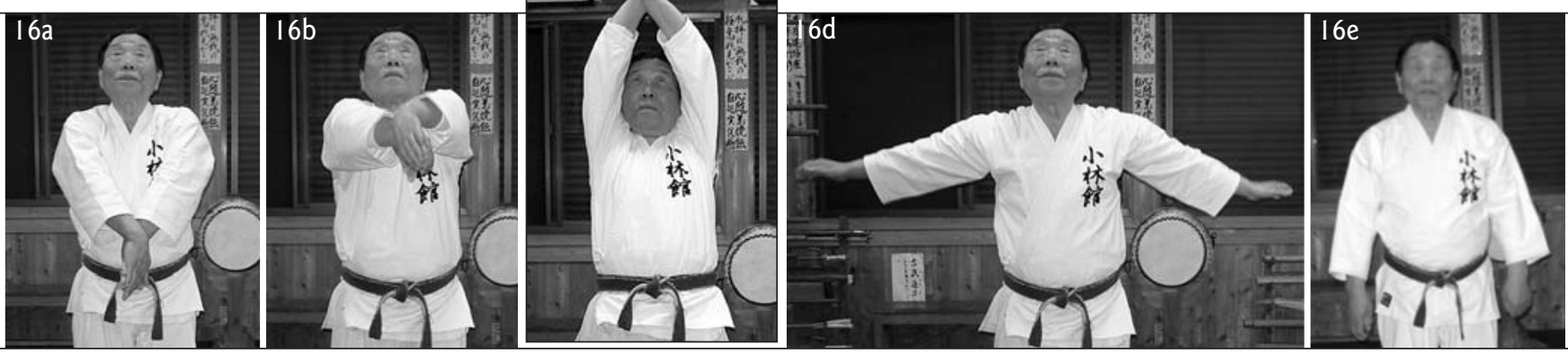


\section{Ejercicio 17}

Adopta una postura natural con los pies, y junta las manos detrás de ti, descansando en la parte inferior de la espalda, con la mano derecha sosteniendo la palma izquierda. Ahora, inclina la cabeza hacia delante y hacia atrás, dejando caer tu barbilla hacia el pecho y elevándola hacia el techo. Mantén la mandíbula cerrada mientras realizas este ejercicio entre 5 y 10 veces.

\section{Ejercicio 18}

En la misma posición, con tu espalda recta, gira la cabeza hacia la izquierda y después vuelve para girar hacia la derecha. Como en el anterior ejercicio, haz esto de 5 a 10 veces, y luego continúa.

\section{Ejercicio 19}

Manteniendo la misma posición, inclina tu cabeza a la izquierda como si tu oreja fuese a tocar tu hombro, vuelve arriba, y a continuación inclina tu cabeza hacia la derecha. Haz esto de 5 a 10 veces.

\section{Ejercicio 20}

Con el cuerpo como en el ejercicio anterior, deja caer lentamente tu cabeza hacia delante y gira tu cuello hacia la izquierda, después hacia atrás, hacia la derecha, hacia adelante, y luego eleva la cabeza hasta la posición inicial antes de llevarla nuevamente hacia abajo para girar hacia el lado contrario. Haz esto varias veces.
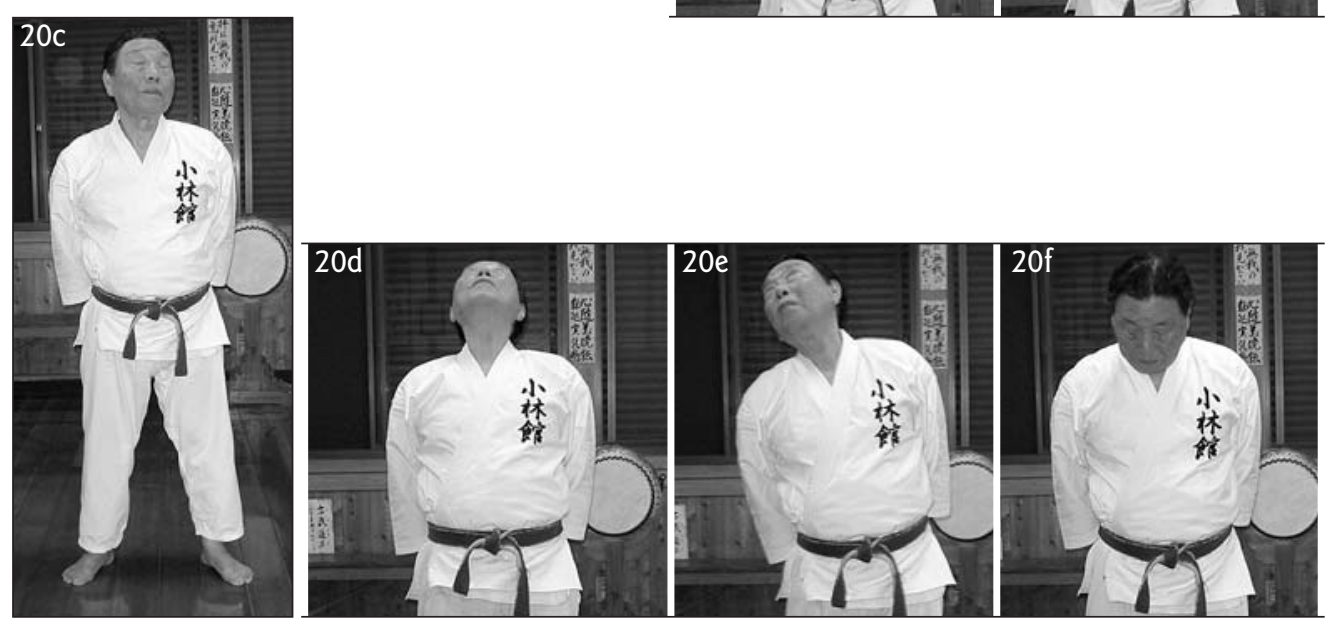
La suavidad y la debilidad triunfarán sobre la fuerza dura.

$\sim$ Laozi

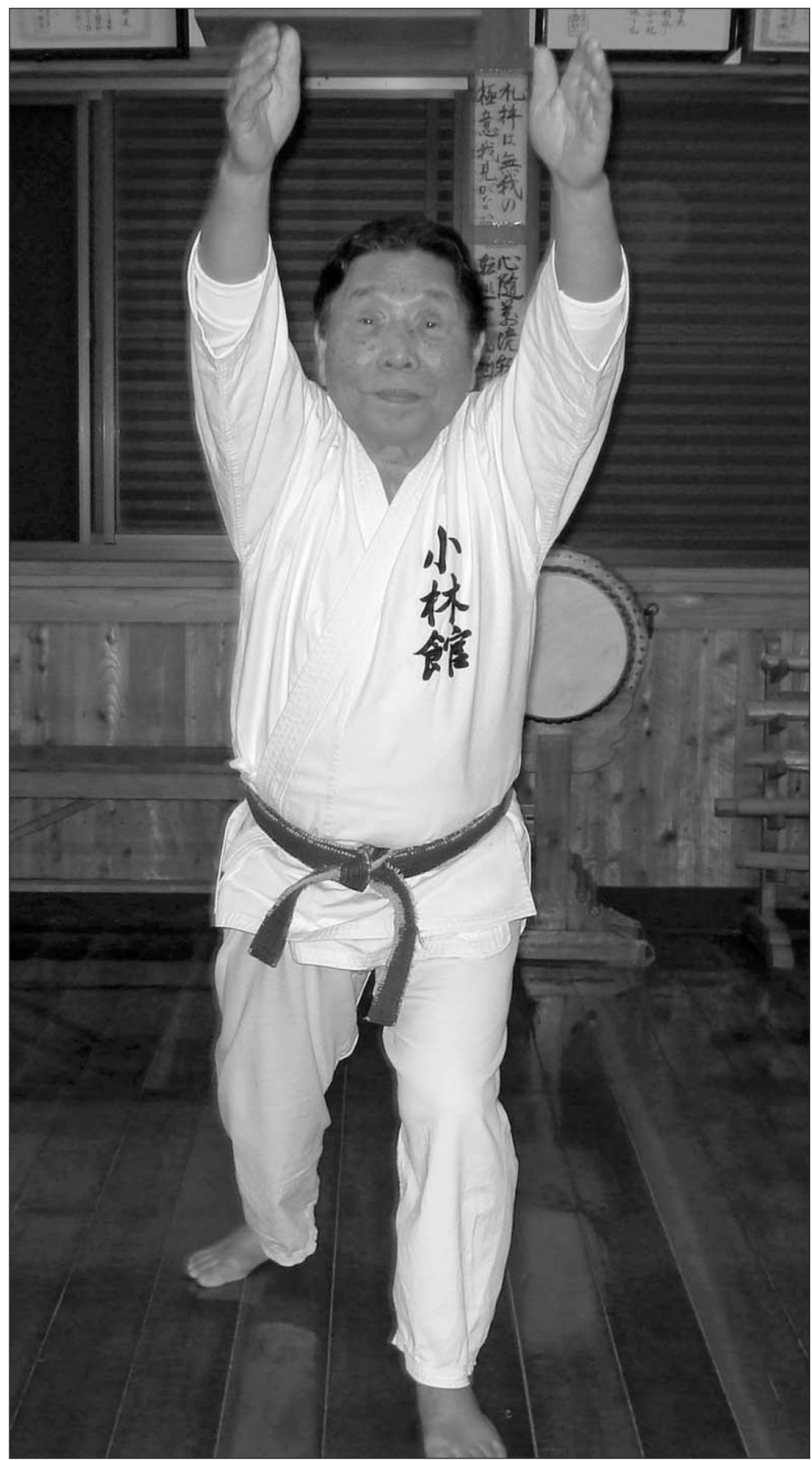


Así finaliza el conjunto de ejercicios, pero recuerda que éstos son extremadamente buenos para el cuerpo, y que cuando hayas completado los mismos tu cuerpo se sentirá bien porque estará flexible y relajado. Esto incrementará tu flexibilidad, acondicionará tu respiración, y relajará tu cuerpo y equilibrará tu espíritu. Incluso para personas que no practican las artes marciales, tengo confianza de que simplemente haciendo estos ejercicios preservarán la salud de su cuerpo, harán reposar al espíritu y ayudarán a mantener la juventud. Para aquellos que practican artes marciales, puesto que endurecer el cuerpo tanto como se pueda es incorrecto, por favor estad informados de que temo que si no hacéis estos ejercicios perderéis la armonía de vuestro cuerpo. Así como los sauces nunca se rompen bajo el peso de la nieve, un cuerpo flexible y ágil no se romperá bajo condiciones de estrés. Con el objeto de llegar a ser verdaderamente fuerte, trabaja en el fortalecimiento del cuerpo, observando la parte dura del entrenamiento, pero no descuides la parte suave. Si eres capaz de comprender tanto la fuerza como la suavidad, te mostrarás como un artista marcial verdaderamente espléndido.

Desde hace mucho tiempo han existido numerosos profesores de kárate longevos. Creo que esto es quizá porque su entrenamiento comportó un seguimiento diligente de los principios de la dureza y la suavidad.

Matsumura Sokon falleció en 1892 a la edad de 92. Itosu Anko falleció en 1915 a la edad de 85. Funakoshi Gichin murió en 1957 a la edad de 88. Kyoda Juhatsu falleció en 1968 a la edad de 82. Chibana Choshin falleció a la edad de 85, en 1969. Otsuka Hironori falleció en 1982 a la edad de 89. Konishi Yasuhiro murió en 1983 a la edad de 89. Iraha Choko falleció en 1986 a la edad de 86. Gima Makoto falleció a los 93 años, en 1989.

Si tu cuerpo sólo se entrena para ser duro, se desajustará totalmente. Con el objeto de recuperarse de cualquier fallo que pueda ocurrir, necesitarás parar de entrenar. Recuerda, el kárate es como el agua caliente, si no se calienta constantemente volverá simplemente a ser agua. Éste es el decimoprimero de los "20 principios del Kárate" de Funakoshi. Un buen modo de pensar en ello es que un día de entrenamiento perdido son tres días que necesitarás para recuperarlo. La velocidad a la que se pierden las ganancias es así de rápida.

El hacerse tan mayor como para no poder entrenar kárate es terrible. El director de la Shindo Jinen-Ryu, Konishi Yasuhiro, a menudo decía "Mi kárate no es lo suficientemente bueno, por tanto continuo entrenando hasta el próximo mundo". El fundador de la Wado-ryu, Otsuka Hironori, diría "Los verdaderos expertos marciales entrenan todos los días hasta que mueren”. Yo, personalmente, espero que mi cuerpo me permita hacer kárate para siempre.

He oído que el experto de judo Mifune Kyuzo, $10^{\circ}$ Dan, incluso cuando era muy anciano, tenía un cuerpo aún ágil, y que el modo en que se movía era muy relajado, sus movimientos eran rápidos, y fue un practicante de judo activo hasta justo antes de su muerte. Mifune también vivió más de 80 años.

Otro ejemplo es el fundador del aikido, Ueshiba Morihei, que vivió más de 80 años, y su aikido era más fuerte justo antes de morir. Esto es precisamente lo que quiero aclarar. Los grandes expertos de las artes marciales tienen la mejor técnica hasta el momento en el que la chispa de su vida se extingue, y nunca abandonan este camino. Preservar la longevidad y ser capaz de entrenar siempre seriamente es una tarea difícil. No es algo que puedan hacer muchas personas. Sin embargo, si las personas fuesen capaces de hacer esto en alguna pequeña medida, yo no encontraría mayor alegría. Para que puedas obtener estos beneficios, espero que no te equivoques en tus métodos de entrenamiento y que siempre seas capaz de entrenar diligentemente en kárate.

\section{Cuando las}

personas nacen

son suaves,

pero cuando

mueren se han

vuelto duras.

$\sim$ Laozi

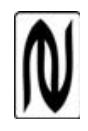

Revista de Artes Marciales Asiáticas $\diamond$ Volumen 4 Número 1 (94-103) - 2009 